\title{
The Effects of Dexmedetomidine on Hemodynamic Parameters and Intubation Conditions
}

\author{
(1) Arzu Yıldırım Ar1, (1) Fatma Nur Kaya², Belgin Yavaşcaoğlu², Elif Başağan Moğol2 \\ ${ }^{1}$ Department of Anesthesiology and Reanimation, Health Sciences University Fatih Sultan Mehmet Health Application \\ Research Center, Istanbul, Turkey \\ ${ }^{2}$ Department of Anesthesiology and Reanimation, Uludag University Faculty of Medicine, Bursa, Turkey
}

\begin{abstract}
Introduction: In this study, we aim to investigate the effects of two different preanesthetic doses of dexmedetomidine on the hemodynamic response to endotracheal intubation, intubation conditions and neuromuscular block.

Methods: Seventy-five ASAI-II patients, aged 18-70 years, who required tracheal intubation for elective surgery were allocated for this study. Before induction, patients were randomly divided into three groups to receive either saline as placebo (20cc) (GroupC), dexmedetomidine $0.5 \mu \mathrm{g} / \mathrm{kg}$ (Group D0.5) or dexmedetomidine 1 $\mu \mathrm{g} / \mathrm{kg}$ (Group D1) in a total volume of 20 $\mathrm{cc}$ in $10 \mathrm{~min}$. Heart rate(HR) and mean arterial pressure (MAP) were recorded according to the study's measurement time. Time to achieve $90 \%$ and 100\% neuromuscular block, time to recovery from neuromuscular block 25\% (T25), 50\% (T50), 75\% (T75) and recovery index values were noted.

Results: The increases in HR after laryngoscopy and immediately intubation were lower in both groups D than Group C. Values of MAP during laryngoscopy were lower in both Groups D than Group C Times to achieve 90\% and 100\% neuromuscular block were found significantly lower in dexmedetomidine groups than Group C. Values of T75 and recovery index in Group D 0.5, T25, T50, T75 and recovery index in Group D1 were longer than Group C. Neuromuscular block properties were similar between dexmedetomidine groups.

Discussion and Conclusion: We conclude that dexmedetomidine decreased hemodynamic response to endotracheal intubation, especially heart rate dose-dependently, whereas it decreased time to achieve neuromuscular block and increased time to recovery from the neuromuscular block as independent from dose.

Keywords: Dexmedetomidine; hemodynamic response; intubation; neuromuscular blockage.
\end{abstract}

$\mathrm{T}$ he time from induction of anesthesia and subsequent loss of consciousness to endotracheal intubation is one of the most important stages of anesthesia because of acute and dramatic changes occur in the cardiovascular and respiratory system. Direct laryngoscopy and tracheal intubation potentially increase sympathetic response. Significant increases in plasma adrenaline and noradrenaline levels have been reported within the first five minutes after intubation, which then return to pre-induction values ${ }^{[1]}$.
As a result, tachycardia, hypertension and cardiac arrhythmias may frequently, and hypotension and bradycardia may rarely be encountered. The main reason for the sympathoadrenal response to endotracheal intubation is the stimulation of the supraglottic region ${ }^{[2,3]}$. Hemodynamic changes begin with laryngoscopy, reach a maximum level within 1-2 minutes, and return to pre-laryngoscopy values after approximately five minutes. While these transient hemodynamic responses do not cause significant problems in

Correspondence (İletişim): Arzu Yıldırım Ar, M.D. Saglik Bilimleri Universitesi Fatih Sultan Mehmet SUAM, Istanbul, Turkey Phone (Telefon): +90 5053822729 E-mail (E-posta): dr.arzuyildirim@hotmail.com 
healthy individuals, they may have negative consequences in risky cases ${ }^{[1]}$. In anesthesia practice, to suppress hemodynamic responses to laryngoscopy and tracheal intubation; in addition to pharmacological approach, glossopharyngeal and superior laryngeal nerve blocks can be applied with various drugs ${ }^{[4-6]}$. Bolus and infusion applications of dexmedetomidine suppress sympathetic activation in endotracheal intubation and extubation ${ }^{[7-9]}$. Tissue perfusion decreases due to decrease in cardiac output and blood pressure secondary to sympatholytic activation of central and peripheral pathways following infusion of its loading dose with resultant alterations in distribution kinetics of rocuronium, prolongation of recovery from neuromuscular block, and decrease in the requirement for musculorelaxant drugs ${ }^{[10]}$. Dexmedetomidine has found widespread use in many areas of daily anesthesia practice because of its inhibition of sympathetic activity, and reduction in hemodynamic response with its effects on sympathetic nerve endings, induction of sedation, anxiolysis and analgesia with its anesthetic and opioid protective effect without any impact on spontaneous breathing ${ }^{[11,12]}$. In our prospective, randomized, placebo-controlled, double-blind study, we aimed to evaluate the effects of two different doses of dexmedetomidine $(0.5 \mu \mathrm{g} / \mathrm{kg}$ and $1 \mu \mathrm{g} / \mathrm{kg})$ before induction on hemodynamic responses related to intubation, intubation conditions, and neuromuscular block.

\section{Materials and Methods}

Our study was planned as a randomized placebo-controlled and double-blind trial upon the decision of Uludağ University Faculty of Medicine' Health Application and Research Center (B.30.2.ULU.0.01.00.01.02.020/8292) and after approval of the Ethics Committee was obtained. Seventy-five ASA I-II patients aged 18-70 years who would undergo endotracheal intubation under general anesthesia and elective conditions were included in the study. For this study, patients who could be placed in a prone position on the operation table with one arm left outside the operation area were selected for neuromuscular monitoring. Before this study, each patient was informed about the study, and written consent was obtained from the volunteers who agreed to participate.

Patients with heart, liver, renal failure, morbid obesity, a history of allergy to drugs used in this study and suspect pregnancy, patients who were using drugs known to affect neuromuscular transmission and who were expected to have intubation difficulties were excluded from this study. The cases were divided into three groups before induction according to the closed envelope method as follows:

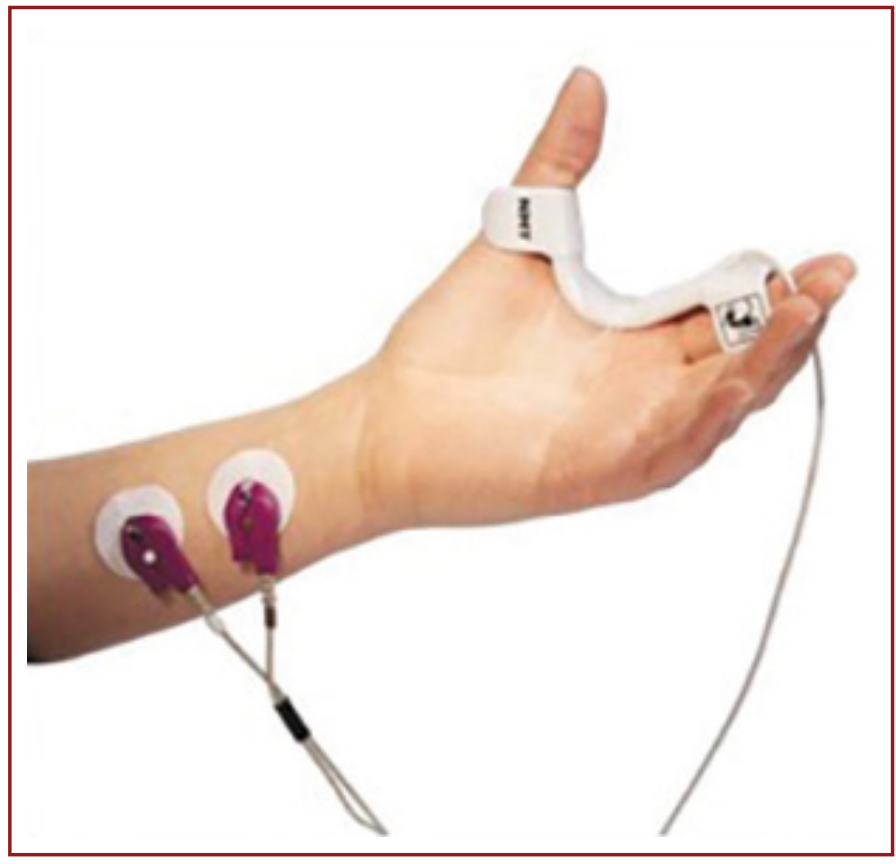

Figure 1. Neuromuscular monitorization.

dexmedetomidine $0.5 \mu \mathrm{g} / \mathrm{kg}$ (Group D 0.5, $\mathrm{n}=25), 1 \mu \mathrm{g} / \mathrm{kg}$ dexmedetomidine (Group D 1, $\mathrm{n}=25$ ) or saline (SF) (Group $C, n=25)$. Standard D-II derivation electrocardiography, noninvasive blood pressure, end-tidal carbon dioxide concentration $\left(\mathrm{ETCO}_{2}\right)$ and peripheral oxygen saturation $\left(\mathrm{SpO}_{2}\right)$ monitoring were performed using Datex-Ohmeda Cardiocap $^{\mathrm{TM}} / 5$ (GE, Finland) device. A $20 \mathrm{G}$ iv cannula was inserted into the back of the hand, and $0.9 \% \mathrm{NaCl}$ infusion was started at a rate of $7 \mathrm{mg} / \mathrm{kg} / \mathrm{h}$. Before administration, the Datex-Ohmeda Cardiocap ${ }^{\mathrm{TM}} / 5$ (GE, Finland) device was placed between the thumbs and index fingers of the hands to be monitored to assess neuromuscular conduction. The ulnar nerve was preferred for neuromuscular monitoring. The ulnar artery was palpated, and the location of the ulnar nerve was determined. This area was cleaned with alcohol, and after drying, two electrodes (active electrode on the distal, and inactive electrode on the proximal part) were attached along the ulnar nerve tracing at the level of wrist fold (Fig. 1).

The drugs used in this study were prepared by a physician who did not participate in this study and diluted with saline to a total amount of $20 \mathrm{cc}$. Also, $20 \mathrm{cc}$ SF was prepared to be applied in Group C. Study medications were administered within ten minutes as an infusion before induction. After induction of anesthesia, $2 \mathrm{mg} / \mathrm{kg}$ propofol and $1 \mu \mathrm{g} /$ $\mathrm{kg}$ fentanyl were administered, and the patient was made unconscious. Then, supramaximal stimulation was administered to obtain a $100 \%$ control value by neuromuscular 
Table 1. Intubation scores

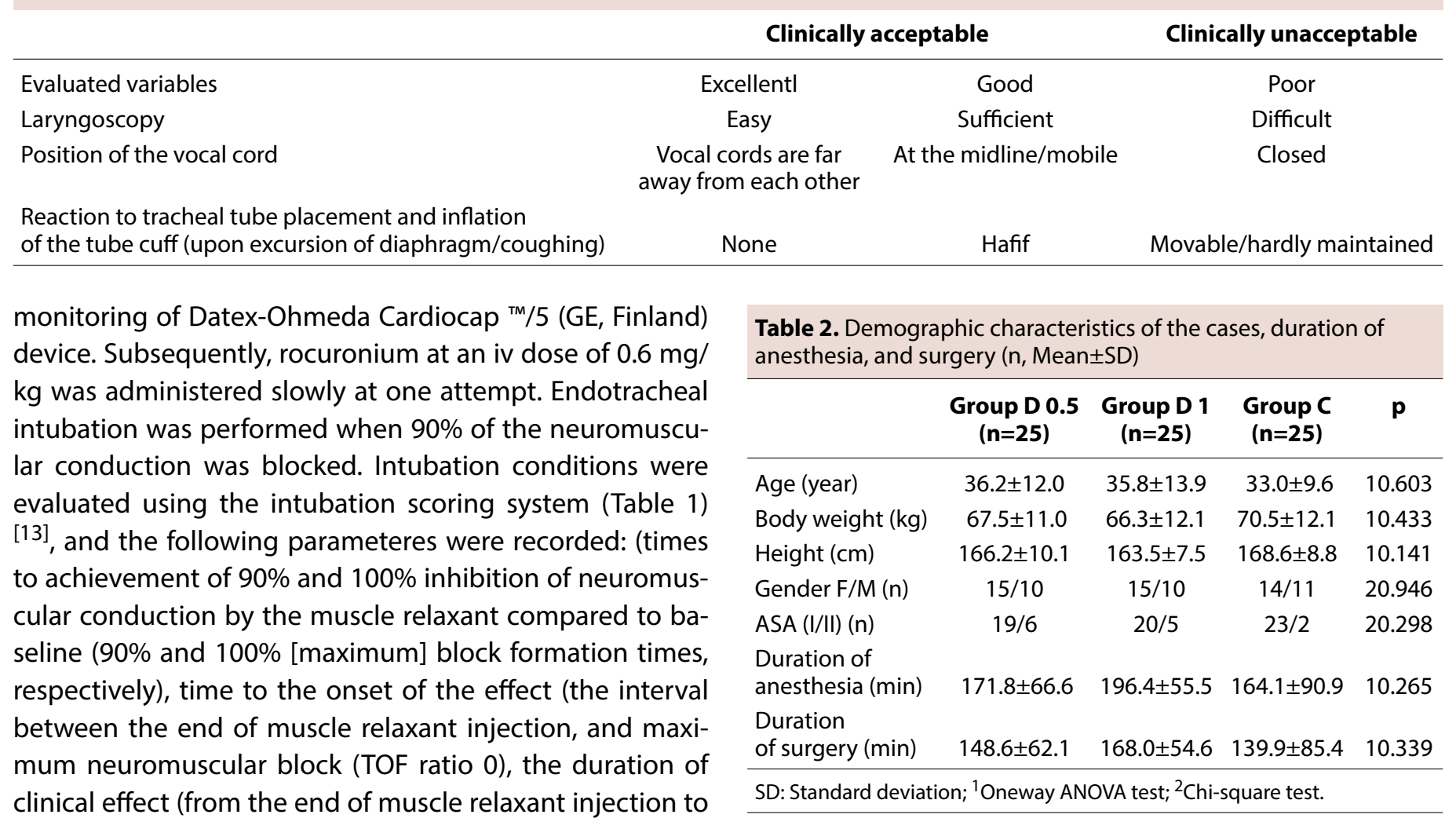
the return of neuromuscular conduction at $25 \%, 50 \%$ and $75 \%$ of baseline value; T25, T50 and T75) and recovery index (the time interval elapsed between $25 \%$ to $75 \%$ recovery from a neuromuscular block).

Mechanical ventilation was performed for all cases to achieve $\mathrm{ETCO}_{2}$ values of $35-40 \mathrm{mmHg}$. Anesthesia was maintained with a mixture of $1-2 \%$ sevoflurane and $50 \% \mathrm{O} 2+$ $\mathrm{N} 2 \mathrm{O}$. When the perioperative TOF value was 2 , an additional dose of $0.15 \mathrm{mg} / \mathrm{kg}$ rocuronium was administered. Heart rate (HR), mean arterial blood pressure (MAP), $\mathrm{SpO}_{2}$ and $\mathrm{ETCO}_{2}$ values of the subjects were recorded before $(Z 1)$, after administration (Z2), before induction (Z3), after induction (Z4), during laryngoscopy (Z5), immediately after intubation (Z6), 1, 3, 5, 10 and 15 minutes after intubation (Z7, Z8, Z9, Z10 and Z11, respectively). Complications (e.g. bradycardia, hypotension, drug allergy, sore throat, nausea and vomiting) were observed during the operation, and at postoperative 24 . hour were recorded.

Hypotension was defined as a decrease in MAP of more than $25 \%$ for 60 secs compared to the baseline value, and it was treated with 5-10 mg iv ephedrine.

Bradycardia was defined as HR of $<45$ bpm for 60 secs and treated with $0.5 \mathrm{mg}$ iv atropine. In the presence of nausea and vomiting, administration of $20 \mathrm{mg}$ iv metoclopramide was planned.

Statistical analysis of the data was performed using SPSS 13.0 statistical package program. Shapiro-Wilk test was used to determine whether the data showed normal distribution. Mann-Whitney $U$ test was used for comparison of two groups and Kruskal-Wallis test was employed for comparison of more than two groups.

The relationships between the variables were analyzed with Pearson correlation and Spearman correlation coefficients. Pearson chi-square test and Fisher's exact chi-square test were used to analyze the categorical data. Statistical analyzes were considered significant when $p<0.05$.

\section{Results}

None of the 75 patients included in this study were excluded. Age, body weight, height, gender, ASA group, duration of anesthesia and surgery were similar (Table 2). There was no difference between total rocuronium doses used. When HRs were compared between groups, the changes in HRs in the Z2, Z3, Z6 and Z7 periods in the Group D1 were significantly higher than in the Group D 0.5, and HRs in the $\mathrm{Z2}, \mathrm{Z3}, \mathrm{Z4}, \mathrm{Z} 5$ and Z6 periods in the Group D 0.5 were lower when compared with the Group C. When Group D 1 and Group C were compared, HR values in Group D1 were lower in Z2, Z3, Z4, Z5, Z6 and Z7 periods when compared with those of Group C (Fig. 2). 


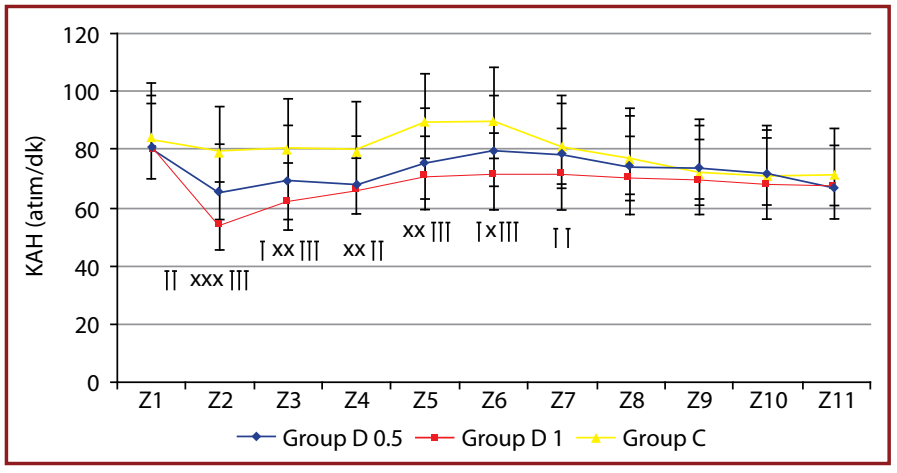

Figure 2. Distribution of heart rate (HR) values by groups (Means $\pm S D$ ). $\mathrm{Z1:}$ Before the study drug is given (control); Z2: After the study drug is given; Z3: Before induction; Z4: After induction; Z5: During laryngoscopy; Z6: Immediately after intubation; Z7: 1 minute after intubation; Z8: 3 minutes after intubation; Z9: 5 minutes after intubation; Z10: 10 minutes after intubation; Z11: 15 minutes after intubation; Group D 0.5 compared with Group $D 1 ;\rceil: p<0.05$, t7: $p<0.001$; Group D 0.5 compared with Group $C ; x: p<0.05, x \times: p<0.01, x \times x$ : $p<0.001$; Group D 1 compared with Group C; : $p<0.05$, IT $p<0.01$, IT: $p<0.001$.

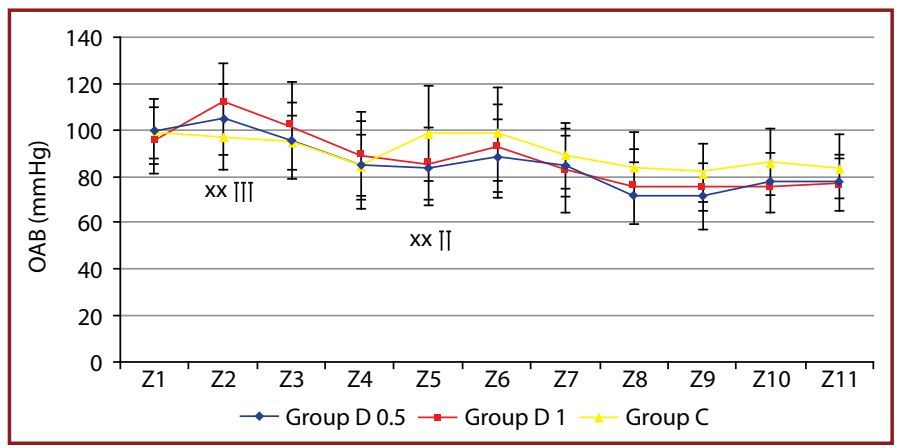

Figure 3. Distribution of Mean arterial blood pressure (MAP) values by groups (Means $\pm S D$ ).

OAB: MAP (mmHg); Z1: Before the study drug is given (control); Z2: After the study drug is given; Z3: Before induction; Z4: After induction; Z5: During laryngoscopy; Z6: Immediately after intubation; Z7: 1 minute after intubation; Z8: 3 minutes after intubation; Z9: 5 minutes after intubation; Z10: 10 minutes after intubation; Z11: 15 minutes after intubation; Group D 0.5 compared with Group C; $\times x: p<0.01$; Group D 1 compared with Group C; T; $p<0.01$, IT: $p<0.001$.

When the intra-group MAP values were compared, Z2 period values were higher in Groups D 0.5 and D 1 than in Group $C(p<0.01, p<0.001$, respectively). In addition, the values in Groups D 0.5 and D 1 were lower in the Z5 period when compared with Group $C(p<0.01, p<0.01$, respectively) (Fig. 3). There was no significant difference in $\mathrm{SpO}_{2}$ and $\mathrm{ETCO}_{2}$ values of the cases.

Intraoperative and postoperative complications requiring treatment are shown in Table 3.

The intraoperative bradycardia was significantly higher in Group D 1 than in Group C $(p<0.05)$. In the postoperative period, the incidence of nausea and vomiting was significantly lower in Group D than Group C $(p<0.01)$. When the $90 \%$ and $100 \%$ block formation times of the cases were
Table 3. Intraoperative and postoperative complications

\begin{tabular}{|c|c|c|c|c|c|c|}
\hline & \multicolumn{2}{|c|}{$\begin{array}{c}\text { Group D } 0.5 \\
(n=25)\end{array}$} & \multicolumn{2}{|c|}{$\begin{array}{c}\text { Group D } 1 \\
(n=25)\end{array}$} & \multicolumn{2}{|c|}{$\begin{array}{c}\text { Group C } \\
(n=25)\end{array}$} \\
\hline & $\mathbf{n}$ & $\%$ & $\mathbf{n}$ & $\%$ & $\mathbf{n}$ & $\%$ \\
\hline \multicolumn{7}{|l|}{ Intraoperative period } \\
\hline Bradycardia & 3 & 12 & 9 & $36^{*}$ & 2 & 8 \\
\hline Hypotension & 3 & 12 & 0 & 0 & 0 & 0 \\
\hline \multicolumn{7}{|l|}{ Postoperative period } \\
\hline Bradychardia & 0 & 0 & 1 & 4 & 0 & 0 \\
\hline Nausea, vomiting & 2 & 8 & 0 & $0^{* *}$ & 7 & 28 \\
\hline
\end{tabular}

Table 4. Comparison of characteristics of neuromuscular block (Mean \pm SD)

\begin{tabular}{lccc}
\hline & $\begin{array}{c}\text { Group D 0.5 } \\
(\mathbf{n = 2 5})\end{array}$ & $\begin{array}{c}\text { Group D 1 } \\
(\mathbf{n = 2 5 )}\end{array}$ & $\begin{array}{c}\text { Group C } \\
(\mathbf{n = 2 5})\end{array}$ \\
\hline 90\% block time (sec) & $77.8 \pm 19.3^{* *}$ & $83.88 \pm 33.9^{* *}$ & $108.7 \pm 35.8$ \\
100\% block time (sec) & $81.4 \pm 19.2^{* *}$ & $88.64 \pm 35.0^{* *}$ & $113.32 \pm 35.9$ \\
T25 (min) & $56.8 \pm 14.3$ & $60.12 \pm 12.0^{*}$ & $49.84 \pm 16.6$ \\
T50 (min) & $67.80 \pm 16.4$ & $75.16 \pm 15.8^{* *}$ & $49.84 \pm 16.6$ \\
T75 (min) & $83.5 \pm 23.9^{* *}$ & $91.7 \pm 21.7^{* * *}$ & $66.3 \pm 19.8$ \\
Recovery time (min) & $26.7 \pm 14.6^{* *}$ & $30.7 \pm 14.7^{* * *}$ & $16.9 \pm 8.9$ \\
\hline
\end{tabular}

$90 \%$ block time: the time when musculorelaxant agent inhibits neuromuscular conduction at a rate of $90 \%$ when compared with baseline value (optimal time period for intubation); $100 \%$ block time: the time to onset of action; the time interval between the end of musculorelaxant injection and formation of maximum neuromuscular block; T25, T50 and T75: the time interval between the end of musculorelaxant injection and, recovery of neuromuscular conduction up to $25 \%, 50 \%$, and $75 \%$ of the baseline value; Recovery Index: difference between T25 qnd T75 values (T25-T75); ${ }^{*} p<0.05 ;{ }^{* *} p<0.01 ;{ }^{* * *} p<0.001$ in comparison with Group C.

compared, these periods were significantly shorter in Groups D 0.5 and D 1 compared to Group C (for all comparisons; $\mathrm{p}<0.01)$. In addition,there was no significant difference in dexmedetomidine groups (Table 4).

When 25\% (T25), 50\% (T50), 75\% (T75) recovery times and recovery indexes (T75-T25) of the block were compared, T75 and recovery indexes were found to be longer in Group D 0.5 than Group C (respectively; $<0.01, p<0.01$ ). In Group D $1, \mathrm{~T} 25, \mathrm{~T} 50, \mathrm{~T} 75$ and recovery index were longer than Group $C(p<0.05, p<0.01, p<0.001, p<0.001$, respectively). There was no difference between dexmedetomidine groups in terms of these values (Table 4). Intubation scores were similar in all three groups (Fig. 4).

\section{Discussion}

As a selective a2 receptor agonist, dexmedetomidine is frequently used in today's anesthesia practice because it has dose-dependent sedative, anxiolytic and analgesic ef- 


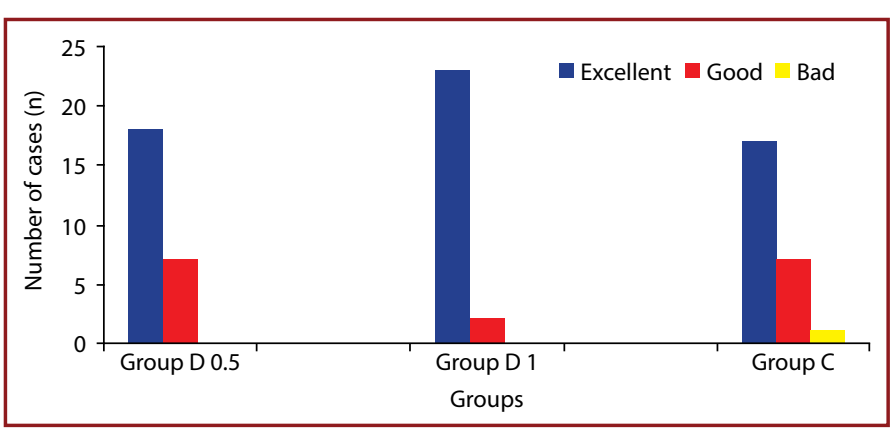

Figure 4. Distribution of intubation scores among groups (n).

fects without inducing respiratory depression. Also, it reduces anesthetic requirement during intraoperative period and provides hemodynamic stability ${ }^{[14-16]}$. The alpha-2 receptors localized in the blood vessels mediate vasoconstriction and those located at sympathetic terminals play a role in the regulation of the autonomic and cardiovascular system by inhibiting norepinephrine release.

Jaakola et al. reported that administration of $0.6 \mu \mathrm{g} / \mathrm{kg}$ iv bolus doses of dexmedetomidine ten min before anesthesia induction suppressed increases in heart rates and arterial pressure due to endotracheal intubation and reduced noradrenaline concentration ${ }^{[17]}$. Yavaşçaoğlu et al. reported that single administration of $0.5 \mu \mathrm{g} / \mathrm{kg}$ iv dose of dexmedetomidine two min before anesthesia induction also prevented hemodynamic stress responses ${ }^{[18]}$.

Kordan et al. administered three different doses of dexmedetomidine $(0.6 \mu \mathrm{g} / \mathrm{kg}, 1 \mu \mathrm{g} / \mathrm{kg}$ and $2 \mu \mathrm{g} / \mathrm{kg})$ with three different administrations ( $1 \mathrm{~min}, 5 \mathrm{~min}$ and $10 \mathrm{~min}$ loading, followed by constant infusion of $0.6 \mu \mathrm{g} / \mathrm{kg} / \mathrm{h}$ in all 3 groups), and reported a decrease in heart rate depending on the dose, whereas a significant decrease was observed in in MAP at four minutes of intubation in the group receiving only $2 \mu \mathrm{g} / \mathrm{kg}$ dexmedetomidine ${ }^{[7]}$. In our study, we observed that dexmedetomidine suppressed dose-related heart rate increases during laryngoscopy and intubation periods. During these periods, HR and MAP values were below the continuous control values in dexmedetomidine groups. In addition, during laryngoscopy where hemodynamic responses were most prominent, increases in MAP were similarly prevented by two different doses of dexmedetomidine.

Researchers reported in the literature that doses of 1-4 $\mu \mathrm{g} /$ $\mathrm{kg}$ of dexmedetomidine may cause a temporary increase in blood pressure and reflex bradycardia. Peripheral vasoconstriction due to a $2 \beta$ receptor activation in peripheral arteriol smooth muscles and subsequent sympatholytic effect due to activation of $\mathrm{a} 2 \mathrm{C}$ receptors are responsible for suppressing noradrenaline release by "negative feedback"mechanism ${ }^{[19-22]}$. Bloor et al. reported a 2-minute infusion of dexmedetomidine at a dose of $1 \mu \mathrm{g} / \mathrm{kg}$ and a significant increase in MAP compared to baseline values in the subsequent first minute ${ }^{[23]}$.

Although it has been reported that slow infusion and low-dose administration of dexmedetomidine may prevent this effect, Hall et al. reported that $7 \%$ increase in blood pressure and $16-18 \%$ decrease in HRs were observed within the first ten minutes even in low-dose infusion applications [24]. In our study, although doses of dexmedetomidine $(0.5 \mu \mathrm{g} / \mathrm{kg}$ and $1 \mu \mathrm{g} / \mathrm{kg})$ were administered slowly, a dose-dependent biphasic effect was observed after administration. Increases in MAP after treatment were similar in both groups, but decreases in HRs were higher in the high dose group.

We observed bradycardia requiring treatment mostly in intraoperative period and in a dose-dependent fashion in dexmedetomidine groups. The incidence of bradycardia was significantly higher in the group where dexmedetomidine was administered at a dose of $1 \mu \mathrm{g} / \mathrm{kg}$. In studies performed, the reason for postoperative bradycardia was thought to be suppressed sympathetic flow and increased vagal tone after the central effect of dexmedetomidine, but in our study, bradycardia extending to the postoperative period was found in one patient in Group D 1 [7]. In addition, complications, such as headache and dry mouth associated with dexmedetomidine administration in the postoperative period, were not observed in any of our cases.

The sedative, anxiolytic, analgesic and sympatholytic properties of dexmedetomidine are thought to play a role in the antiemetic effect. Considering that psychological and emotional factors are also effective in dysfunction of the gut-brain axis, it is possible that the sedative and anxiolytic effects of dexmedetomidine may play a role in the antiemetic effect. Although the effects of intubation were evaluated in our study, the decrease in intraoperative anesthetic and opioid and postoperative analgesic requirements by dexmedetomidine may contribute to antiemetic effect as shown in other studies.

Yıldız et al. emphasized that nausea and vomiting were significantly reduced in patients receiving dexmedetomidine $1 \mu \mathrm{g} / \mathrm{kg} 30$ minutes before surgery ${ }^{[25]}$. Taghinia et al. reported that the need for midazolam and fentanyl decreased as well as the antiemetic requirement during sedation with dexmedetomidine infusion ${ }^{[26]}$. Tobias benefited from the antiemetic properties of dexmedetomidine in three 
children with cyclic vomiting syndrome ${ }^{[27]}$. In our study, the frequency of nausea and vomiting was lower in dexmedetomidine groups than in the control group. While this antiemetic effect was not statistically significant in the group given $0.5 \mu \mathrm{g} / \mathrm{kg}$ dexmedetomidine, it was statistically significant in the group given dexmedetomidine at a dose of $1 \mu \mathrm{g} / \mathrm{kg}$. Nausea and vomiting were not observed in this group. There are studies showing the effects of dexmedetomidine on the neuromuscular block ${ }^{[10,28,29]}$.

In pilot studies performed in rats, dexmedetomidine has been reported to induce muscle relaxation via central a2 adrenergic mechanisms, to reduce electromyographic activity in the hind limbs and to prevent alfentanil-induced muscle rigidity ${ }^{[30]}$. Weinger et al. Investigated the effects of dexmedetomidine $(10,30$ and $100 \mu \mathrm{g} / \mathrm{kg}$ ) on a single episode of depression induced by vecuronium infusion in anesthetized rats. They reported that it did not affect T1 height in the first 30 minutes and that it had minor effects in later periods.

They suggested that neuromuscular blocking properties may be independent of the neuromuscular junction and may be due to secondary mechanisms such as cardiovascular depression ${ }^{[28]}$. In contrast, Narimatsu et al. studied the in vitro effects of clinical and experimental doses of dexmedetomidine and clonidine on diaphragm isolated from rats under rocuronium-induced neuromuscular blockade. In their study, they reported that high experimental doses instead of clinical doses affect neuromuscular block due to rocuronium ${ }^{[29]}$. In contrast to Weinger et al., they suggested that these effects were shown to block nicotinic acetylcholine receptors after the neuromuscular junction, independent of the $\mathrm{a} 2$ adrenergic agonist effect ${ }^{[28]}$.

In their study, Talke et al. produced a constant plasma concentration with a target-controlled infusion of dexmedetomidine involunteers who were anesthetized with propofol and alfentanil and reported that plasma concentrations of rocuronium increased, $\mathrm{T} 1$ response decreased, systolic blood pressure decreased and finger blood flow decreased. They suggested that vasoconstriction due to dexmedetomidine may be effective in these changes ${ }^{[31]}$. In their clinical studies, Memis et al. performed endotracheal intubation without the use of muscle relaxants after anesthesia induction with propofol and alfentanil, however they used dexmedetomidine (loading dose, $1 \mu \mathrm{g} / \mathrm{kg}$, infusion rate, 0.2 $\mu \mathrm{g} / \mathrm{kg} / \mathrm{hr}$ ), rocuronium, $\mathrm{N}_{2} \mathrm{O}$, and sevoflurane for the maintenance of anesthesia.

They reported that after 15 minutes of intubation, $\mathrm{HR}$ and MAP decreased, T25 increased, recovery time did not chan- ge, the time required to return $90 \%$ of the first stimulus was prolonged, and the total intraoperative requirement of rocuronium decreased ${ }^{[10]}$. They thought that dexmedetomidine administration diminished tissue perfusion as a result of decreases in cardiac output and blood pressure due to central and peripheral sympatholytic activation, altering the distribution kinetics of rocuronium and reducing dose requirements.

In our study, the findings showed that two different doses of dexmedetomidine administered as a single dose before induction of anesthesia shortened $90 \%$ and $100 \%$ block formation times and prolonged T75 and recovery index times. In addition, a dose of $1 \mu \mathrm{g} / \mathrm{kg}$ prolonged the $\mathrm{T} 25$ and T50 recovery times from nerve block. We think that these results may be related to the sympatholytic effects of dexmedetomidine, which is effective in suppressing hemodynamic responses to intubation. However, the relaxation of the smooth muscle tone of propofol used in the induction of anesthesia may also contribute to this effect.

In their study, Yıldız et al. used the Goldberg intubation scale to evaluate the intubation status and observed that dexmedetomidine had positive effects on intubation conditions ${ }^{[25]}$. In our study, no statistical difference was found between the groups in terms of intubation scores. We conclude that endotracheal intubation performed after $90 \%$ block in TOF response in each patient have yielded this result.

In the light of the findings in our study, single-dose administration of dexmedetomidine before rocuronium administration may be advantageous in cases where serial induction and intubation is preferred. Dexmedetomidine may also reduce the need for muscle relaxants in the intraoperative period. In addition, when the infusion of dexmedetomidine is preferred, it should be kept in mind that residual block may develop and neuromuscular blockade should be monitored with neuromuscular monitoring.

As a result, we observed that dexmedetomidine administered in two different doses before induction of anesthesia suppressed hemodynamic responses due to laryngoscopy and intubation, shortened neuromuscular block formation time and prolonged block recovery time. We suggest that a single dose of dexmedetomidine before anesthesia induction may be beneficial in cases where serial induction and intubation is required in risky cases where hemodynamic responses need to be suppressed.

Ethics Committee Approval: Uludag University Faculty of Medicine, Health Application Research Center B.30.2.ULU.0.01.00.01.02.020/8292. 
Peer-review: Externally peer-reviewed.

Authorship Contributions: Concept: A.Y.A., F.N.K., E.B.M.; Design: A.Y.A., F.N.K., B.Y.; Data Collection or Processing: A.Y.A., F.N.K., E.B.M.; Analysis or Interpretation: A.Y.A., F.N.K., B.Y., E.B.M.; Literature Search: A.Y.A., F.N.K., B.Y.; Writing: A.Y.A., F.N.K.

Conflict of Interest: None declared.

Financial Disclosure: The authors declared that this study received no financial support.

\section{References}

1. Kayhan Z. Entübasyonun fizyopatolojik etkileri ve komplikasyonları. Kayhan Z (editor). Klinik Anestezi. Genişletilmiş 3. baskı. Ankara: Logos Yayıncılık; 2004:267-8.

2. Oczenski W, Krenn H, Dahaba AA, Binder M, El-Schahawi-Kienzl $\mathrm{I}$, Jellinek $\mathrm{H}$, et al. Hemodynamic and catecholamine stress responses to insertion of the combitube, laryngeal mask airway or tracheal intubation. Anesth Analg 1999;88:1389-94.

3. Shribman A J, Smith G, Achola K J. Cardiovascular and catecholamine responses to laryngoscopy with and without tracheal intubation. Br J Anaesth 1987;59:295-9.

4. Morgan GE, Mikhail MS, Murray MJ, Larson CP. Tulunay M, Cuhruk H (editors). Havayolunun kontrolü. In: KorkmazT. Klinik Anesteziyoloji. 3. Baskı. Ankara: Güneş Kitabevi; 2004:59-85.

5. Davies NJH, Cashman JN. Havayolu kontrolü. Lee's Synopsis of Anaesthesia. In: Özkoçak Turan I (translation ed.) $13^{\text {th }}$ ed. Ankara: Güneş Tıp Kitabevleri; 2008:201-29.

6. Mikawa K, Nishina K, Maekawa N, Obara H. Comparison of nicardipin, diltiazem and verapamil for controlling the cardiovascular responses to tracheal intubation. $\mathrm{Br} J$ Anaesth 1996;76:221-6.

7. Kordan A, Günaydın B. Farklı dozlarda deksmedetomidinin laringoskopi ve endotrakeal entübasyona karşı oluşan hemodinamik yanıta, peroperatuvar anestezik gereksinimine etkilerinin karşılaştırılması. Anestezi Dergisi 2006;14:95-102.

8. Güler G, Akın A, Tosun Z, Ors S, Esmaoglu A, Boyacı A. Single-dose dexmedetomidine reduces agitation and provides smooth extubation after pediatric adenotonsillectomy. Pediatric Anesthesia 2005;15:762-6.

9. Güler G, Akın A, Tosun Z, Eskitascoglu E, Mızrak A, Boyacı A. Single-dose dexmedetomidine attenuates airway and circulatory reflexes during extubation. Acta Anaesthesiol Scand 2005;49:1088-91.

10. Memiş D, Turan A, Karamanlıoğlu B, Şeker Ş, Pamukçu Z. Dexmedetomidine reduces rocuronium dose requirement in sevoflurane anaesthesia. Current Anaesthesia \& Critical Care 2008;19:169-74.

11. Bekker A, Sturaitis MK. Dexmedetomidine for neurological surgery. Neurosurgery 2005;57:1-10.

12. Dyck JB, Maze M, Haack C, Vuorilehto L, Shafer SL. The pharmacokinetics and hemodynamic effects of intravenous and intramuscular dexmedetomidine hydrochloride in adult human volunteers. Anesthesiology 1993;78:813-20.
13. Fuchs-Buder T, Claudius C, Skovgaard LT, Eriksson LI, Mirakhur RK, Viby-Mogensen J, et al; $8^{\text {th }}$ International Neuromuscular Meeting. Good clinical research practice in pharmacodynamic studies of neuromuscular blocking agents II: the Stockholm revision. Acta Anaesthesiol Scand 2007;51:789-808.

14. Sharma S, Suthar OP, Tak ML, Thanvi A, Paliwal N, Karnawat R. Comparison of esmolol and dexmedetomidine for suppression of hemodynamic response to laryngoscopy and endotracheal intubation in adult patients undergoing elective general surgery: A prospective, randomized controlled double-blinded study. Anesth Essays Res 2018;12:262-6.

15. Wan Hassan WMN, Tan HS, Mohamed Zaini RH. Comparison of the e ects of dexmedetomidine on the induction of anaesthesia using Marsh and Schnider pharmacokinetic models of propofol target-controlled infusion. Malays J Med Sci 2018;25:24-31.

16. Lu Z, Li W, Chen H, Qian Y. E cacy of a DexmedetomidineRemifentanil Combination Compared with a MidazolamRemifentanil Combination for Conscious Sedation During Therapeutic Endoscopic Retrograde Cholangio-Pancreatography: A Prospective, Randomized, Single-Blinded Preliminary Trial. Dşg Dis Sci 2018;63:1633-40.

17. Jaakola ML, Melkkilä T, Kanto J, Kallio A, Scheinin H, Scheinin M. Dexmedetomidine reduces intraocular pressure, intubation responses and anaesthetic requirements, in patients undergoing ophthalmic surgery. Br J Anaesth 1992;68:570-5.

18. Yavaşcaoğlu B, Kaya FN, Bozkurt M, Kokmaz S. A comparison of esmolol and dexmedetomidine for attenuation of intraocular pressure and haemodynamic responses to laryngoscopy and tracheal intubation. Eur J Anaesthesiol 2008;25:517-9.

19. Ebert TJ, Hall JE, Barney JA, Uhrich TD, Colinco MD. The effects of increasing plasma concentrations of dexmedetomidine in humans. Anesthesiology 2000;93:382-94.

20. Belleville JP, Ward DS, Bloor BC, Maze M. Effects of intravenous dexmedetomidine in humans I. Sedation, ventilation, and metabolic rate. Anesthesiology 1992;77:1125-33.

21. Aho M, Erkola O, Kallio A, Scheinin H, Korttila K. Comparison of dexmedetomidine and midazolam sedation and antagonism of dexmedetomidine with atipamezole. J Clin Anesth 1993;5:194-203.

22. Shutes BL, Gee SW, Sargel CL, Fink KA, Tobias JD. Dexmedetomidine as single continuous sedative during noninvasive ventilation: Typical usage, hemodynamic effects, and withdrawal. Pediatr Crit Care Med 2018;19:287-97.

23. Bloor BC, Ward DS, Belleville JP, Maze M. Effects of intravenous dexmedetomidine in humans. II. Hemodynamic changes. Anesthesiology 1992;77:1134-42.

24. Hall JE, Uhrich TD, Barney JA, Arain SR, Ebert TJ. Sedative, amnestic, and analgesic properties of small-dose dexmedetomidine. Anesth Analg 2000;90:699-705.

25. Yıldız M, Tavlan A, Tuncer S, Reisli R, Yosunkaya A, Otelcioglu S. Effect of dexmedetomidine on haemodynamic responses to laryngoscopy and intubation. Drugs R D 2006;7:43-52.

26. Taghinia AH, Shapiro FE, Slavin SA. Dexmedetomidine in aes- 
thetic facial surgery: improving anesthetic safety and efficacy. Plast Reconstr Surg 2008;121:269-76.

27. Tobias JD. Dexmedetomidine in treatment of cyclic vomiting syndrome. Paediatr Anaesth 2005;15:709-10.

28. Weinger MB, Partridge BL, Henry AF. Dexmedetomidine does not modify the neuromuscular blocking action of vecuronium in the anaesthetized rat. Br J Anaesth 1995;74:455-7.

29. Narimatsu E, Niiya T, Kawamata $M$, Namiki A. Lack in effects of therapeutic concentrations of dexmedetomidine and clon- idine on the neuromuscular blocking action of rocuronium in isolated rat diaphragms. Anesth Analg 2007;104:1116-20.

30. Weinger MB, Segal IS, Maze M. Dexmedetomidine, acting through central alpha-2 adrenoceptors, prevents opiate-induced muscle rigidity in the rat. Anesthesiology. 1989;71:242-9.

31. Talke PO, Caldwell JE, Richardson CA, Kirkegaard-Nielsen $H$, Stafford M. The effects of dexmedetomidine on neuromuscular blockade in human volunteers. Anesth Analg 1999;88:633-9. 